\title{
Revista

\section{Por uma exploração sensorial e afetiva do real: esboços sobre a dimensão háptica do cinema contemporâneo}

\section{For a sensory and affective exploration of reality: sketches on the haptic dimension of contemporary cinema}

\section{ERLY VIEIRA JR.}

Doutor em Comunicação e Cultura (UFRJ). Professor do Programa de Pós-Graduação em Artes (Ufes). Linha de pesquisa: Práticas e Processos Comunicacionais.

<erlyvieirair@hotmail.com>

\section{RESUMO}

Este artigo pretende investigar a dimensão háptica (tanto visual quanto sonora) presente no chamado "cinema de fluxo", vertente transnacional do cinema das duas últimas décadas, marcada pela emergência de um realismo sensório. Trata-se de um cinema cujas narrativas são calcadas em ambiências e por uma experiência audiovisual conduzida pela sobrevalorização de uma sensorialidade multilinear e dispersiva, ampliadas pela presença de um complexo desenho de som. Nossa abordagem será centrada em dois aspectos: de um lado, a conceituação do realismo sensório dentro do panorama do cinema contemporâneo; do outro, as manifestações de uma

\section{ABSTRACT}

This paper aims to investigate the haptic dimension (both, visual and sound) which is present in the called "flow cinema", transnational strand of cinema of the past two decades, marked by the emergence of a sensory realism. This is a cinema that the narrative is modeled on ambiance and an audiovisual experience driven by the overvaluation of a multilinear dispersive and sensuousness, magnified by the presence of a complex sound design. Our approach will focus on two aspects: on one hand, the concept of sensory realism within the panorama of contemporary cinema; the other, the manifestations of a more tactile than 
visualidade háptica, mais tátil do que óptica (Marks, 2000; Bruno, 2010) e de uma escuta háptica, capaz de instalar um estado de ambiguidade na percepção sonora (Marks, 2000) na construção narrativa dos filmes do "cinema de fluxo". Tais conceitos serão aplicados na análise de obras de cineastas como Naomi Kawase, Claire Denis, Apichtatpong Weerasethakul e Hou Hsiao-Hsien.

Palavras-chave: Cinema contemporâneo. Realismo sensório. Visualidade háptica. optical (Marks, 2000; Bruno, 2010) haptic visuality and a haptic listening, able to install a state of ambiguity in sound perception (Marks, 2000) in the construction of narrative films the "flow cinema". These concepts will be applied in the analysis of works of filmmakers like Naomi Kawase, Claire Denis, Hou Hsiao Apichtatpong Weerasethakul and Hsien.

Keywords: Contemporary cinema. Sensory realism. Haptic visuality.

Se o debate crítico no cinema contemporâneo chama a atenção, neste início de Século, para a emergência de um conjunto de filmes marcado pela construção narrativa através de ambiências e ambiguidades narrativas, pela adoção de um olhar microscópico sobre o espaço-tempo cotidiano e por uma experiência afetiva pautada pela presença de uma sensorialidade multilinear e dispersiva, cabe aqui pensarmos como esse cinema ressignifica alguns pressupostos da linguagem audiovisual, para estabelecer esse outro contrato sensorial junto ao espectador.

Costumam ser arrolados sob a rubrica de um "cinema de fluxo" (Oliveira, 2010), obras produzidas a partir do final dos anos 90, por realizadores tão distintos entre si quanto Hou Hsiao-Hsien, Apichatpong Weerasethakul, Claire Denis, Gus Van Sant Lucrecia Martel e Naomi Kawase. Em comum, tais filmes possuem essa predileção de uma forma de narrar na qual o sensorial é sobrevalorizado como dimensão primordial para o estabelecimento de uma experiência estética junto ao espectador: em lugar de se explicar tudo com ações e diálogos aos quais a narrativa está submetida, adota-se aqui um certo tom de ambiguidade visual e textual que permite a apreensão de outros 
sentidos inerentes à imagem. Ou seja, trata-se de outra pedagogia do visual e do sonoro, muitas vezes aliado a certa dose de tatilidade na imagem, aquilo que Marks denomina uma "visualidade háptica" (Marks, 2000), que nos convida a reaprender a ver e ouvir um filme, para além de uma certa anestesia de sentidos que as convenções do cinema hegemônico (mesmo o contemporâneo, com suas desconstruções narrativaspósmodernase choques perceptivos proporcionados pelo 3D) há muito promovera em nossos corpos de espectadores.

Numa época em que o sensorial é espetacularizado (e, muitas vezes, anestesiado, como nos blockbusters "tridimensionais" que monopolizam as programações das salas exibidoras comerciais mundo afora), valorizar o aspecto micro em lugar do macro soa-me como um sugestivo convite à subversão da lógica industrial. Daí a adoção de uma sensorialidade difusa, multiforme, reticular e dispersiva - e, nesse ponto, ela seria distinta das propostas sensoriais das vanguardas do começo do século $X X$ ou do cinema moderno de um Tarkovski, que aliaria tal dimensão sensorial a conexão com a dialética memória/esquecimento. Aqui, os afetos eclodiriam dentro do plano, não necessariamente atrelados ao cerne narrativo da cena. É como se compusessem um registro paralelo, capaz de tensionar nossa percepção do conjunto de simultâneos microeventos e microdeslocamentos corporais registrados pela câmera, construindo um espaço-tempo narrativo que concebe o cotidiano como uma experiência de sobrevalorização sensorial, a reverberar diretamente no corpo e nos sentidos do espectador.

Podemos dizer que, dentro do cinema de fluxo, a adoção de um olhar que tende ao microscópico e que se deixa guiar pelas sutis modulações de detalhes sonoros, cinéticos e luminosos no interior da cena recoloca a questão do cotidiano sob outra perspectiva narrativa: a que assume o caráter sensorial como ponto de partida para a irrupção de alumbramentos capazes de abrir a percepção do espectador para além 
do anestesiado olhar que já não percebe a riqueza multidimensional de um mundo em constante mobilidade. Daí pensarmos num tipo de plano em que o corte não seja dado pelo final da ação, mas sim por elementos que apontem para a migração espaçotemporal dos afetos irrompidos junto ao espectador durante os eventos filmados/ presenciados.

Schøllhammer (2012), ao discutir o realismo nas artes e literatura contemporâneas, fala de uma "estética afetiva", contraposta à estética do efeito praticada a partir do final do século XX (e traduzida em especial no "realismo traumático" identificado por Hal Foster em seu livro "The return of the real", de 1994). A partir de uma experiência desencadeadora de interssubjetividades afetivas, a obra de arte torna-se real "com a potência de um evento que envolve o sujeito sensivelmente no desdobramento de sua realização no mundo" (Schøllhammer, 2012, p. 138). Ao dissolver a fronteira entre a realidade exposta e a realidade esteticamente envolvida, esse "realismo afetivo" traria a ação do sujeito para dentro do evento da obra.

Esse tipo de "suspensão" entre o eu e o outro, de "entre-lugar" por onde transitam e transferem-se afetos, poderia encontrar paralelo no cinema contemporâneo, a partir da exploração do sensorial como portas de entrada para a imersão do espectador na fugacidade do instante presente em que se desdobra a ação fílmica. Daí a proposição de um "realismo sensório", espécie de desdobramento do realismo afetivo proposto por Schøllhammer, em que a valorização desses aspectos sensíveis produza essa aproximação entre sujeito e obra. Afinal, tais aspectos propõem um diálogo imediato com a alteridade na própria dimensão do corpo e de sua dimensão sensível, sem a necessidade de se organizar como estruturas e precedendo o sentido linguístico.

Podemos pensar o conjunto de filmes analisados como embebido por tal lógica, uma vez que seu caráter assumidamente sensorial permite que sensações e afetos transbordem por entre corpos (filmados e espectatoriais) e espaços. Corpos povoados 
por intensidades (no sentido deluziano de um "corpo sem órgãos") que os adentram a partir da pele, já que estamos falando de um cinema que lida com uma relação física entre câmera e atores. Daí pensarmos numa "câmera-corpo", em estado de "semiembriaguez", a apreender sensorialmente a intensidade da experiência que captura, possibilitando uma mediação pulsante junto ao espectador contemporâneo.

Cabe a essa câmera escoar por entre o transbordamento de afetos entre todos esses corpos filmados e o próprio corpo do espectador - e ela o faz passeando por entre os espaços, sem nunca, porém buscar cristalizar ou petrificar as transições e nuances de intensidades decorrentes desse encontro entre corpos diversos, construindo uma relação bastante física com o mundo que retrata. Por explorar minuciosamente o corpo na tela, a câmera-corpo afeta o próprio espectador, provocando a sensação de se estar num constante estado de "embriaguez" em seu percurso pelos espaços e corpos, dialogando sensorialmente com os transbordamentos de um mundo que é pura mobilidade e fluidez, um "aqui-e-agora" no qual cineasta, espectador, câmera e atores estão imersos e também em movimento.

\section{Um cinema à flor da pele?}

Uma possibilidade de se promover essa construção de uma câmera-corpo nas narrativas do realismo sensório talvez possa estar no diálogo que os filmes de certos diretores (em especial Naomi Kawase e Claire Denis) fazem com uma certa visualidade háptica, nos moldes propostos por Marks, em seu livro “The skinof film” (2000). Aqui, a valorização de texturas dos objetos filmados muito de perto buscaria uma espécie de ativação do tato, a partir da memória cultural e sensória de cada espectador. Nesse tipo de visualidade, as imagens percebidas são completadas justamente pela convocação da memória e da imaginação, de modo a conferir outros significados ao que se filma em plano-detalhe, para além de explicações racionais. 
Imaginamos que a recorrência à dimensão háptica da imagem, de certa forma, talvez seja uma atualização de certos conteúdos já presentes nas concepções apresentadas, nos escritos de Bela Balázs na década de 1920, acerca do primeiro plano (em especial de sua capacidade de dotar os fragmentos de realidade ampliados no écran de uma irrecusável potência de adesão junto ao espectador), bem como remeta a uma certa dimensão de reapresentação revelatória do mundo, implícita no conceito epsteiniano de fotogenia. Contudo, tais enunciados ressignificam-se aqui num contexto que leva em consideração a memória corporal do espectador na relação afetiva que se estabelece com a imagem fílmica. Como afirma Bruno, o háptico "constitui o contato recíproco entre o ambiente e nós" (Bruno, 2010, p. 30): é ele que, na condição de abstração heterotópica de se assistir a um filme, nos faz recordar que ainda temos um corpo, com toda sua concretude. É pelo toque que apreendemos o espaço e, enquanto interação sensória, o háptico se aproxima da khinestesis, essa habilidade do corpo em sentir seu próprio movimento no espaço.

Daí talvez o desejo de tocar, que por vezes retorna explicitamente na filmografia de Naomi Kawase, assuma-se como uma forma de se criar um vínculo entre o que nos rodeia (tanto a cineasta quanto o espectador) e experimentar a tentativa de reter o que nos é fugidio e efêmero no cotidiano. Esse desejo de tatear o mundo chega a se manifestar de maneira explícita, em alguns documentários - a mão da cineasta a tocar quem se ama, seja o rosto da avó, em Caracol/Katatsumori (1994), ou a tentativa de enxugar com a ponta do dedo uma lágrima que caíra na bochecha do filho recém-nascido, em Tarachime (2006), ou até mesmo o intangível (como, novamente em Caracol, ela tenta tocar a luz, que acaba por "engolir" seus dedos). Mas também podemos traduzir essa vontade tátil até mesmo no fato dela operar a câmera em seus filmes não-ficcionais, como se aqui o contato com o real fosse mais íntimo e imediato. 
Esse duplo desejo (de tocar o material e de reter o que é efêmero) meio que situa Kawase entre dois mundos: “as imagens e os corpos, o peso da desgraça e o evanescente da beleza, aquilo que se quer desprender e o que se deseja reter, o visível e o invisível" (Lucas, 2008, p. 36). Daí essa busca, tantos nos filmes não-ficcionais quanto nos ficcionais, por captar ou fabricar momentos únicos, "tensionados à beira do abismo do real" (Murillo, 2008, p. 110), que instaurem junto ao espectador essa relação de proximidade excessiva com os objetos e corpos filmados, para enfim dela extrair uma intensidade não quantificável racionalmente.

É também sob uma lógica de exceder e transbordar que se dá a utilização de planos assumidamente hápticos em grande quantidade nos filmes de Claire Denis. Diversos críticos referem-se ao conjunto de sua obra como um "cinema de sensações", que sobrevaloriza essa dimensão corpórea/material do cinema (Beugnet, 2004) para dali extrair uma construção narrativa em blocos que se encadeiam a partir dos afetos que deles imanam. Daí a adoção de uma visualidade grudada às superfícies filmadas, que permite elevar as tensões entre o espaço físico e psicológico, a níveis extremos, em filmes como Bom Trabalho (1999) e Desejo e obsessão (2001).

No caso de Bom trabalho, vemos toda uma asfixiante atmosfera de competição, ressentimento, desejo sexual reprimido e exploração dos limites físicos (situações inerentes ao ambiente de treinamento da Legião Estrangeira) constituir-se a partir de uma visualidade que sobrevalorize os contornos e texturas sensuais dos corpos em movimento, dialogando com a beleza e aridez das formas naturais que compõem a concretude material do cenário desértico. Trata-se de uma estilização visual das formas no espaço, conjugada por uma "harmonia quase atonal" (Jones, 2009) a interligar a extensa cadeia de imagens.

Ao som da ópera de Benjamin Britten, tal estilização atinge o nível coreográfico (graças à parceria com o coreógrafo Bernardo Montet no preparo corporal dos atores), 
conjugando carne, céu, sol, montanhas, deserto numa paisagem que a câmera de Agnes Godard possa explorar muito de perto. Às vezes, numa distância por demais íntima, que nos permita ver a pulsação de uma veia no braço e nos faça apreendê-la como ritmo e textura puros. A repetição incansável e ritualizada dos gestos inerentes ao cotidiano militar, seja nos treinamentos ou nas tarefas de caserna, muitas vezes captados num plano extremamente próximo, por vezes permite uma espécie de suspensão temporal, abrindo espaço para uma abstração sensorial que permita ao olhar do espectador deixar-se levar pela flutuação que conduz tais movimentos, tentando acompanhar a liberação da energia corporal que eles provocam.

Exemplo disso está na cena da dança final, ao som de The rhythm of the night, hit do grupo de eurodance Corona. Nela, o sargento Galoup (interpretado por Denis Lavant), numa pista de dança vazia, empreende um tour de force solitário, em que seu corpo, que carrega em si a memória de cada rito corporal repetidos incontáveis vezes sob o sol escaldante do deserto de Djibouti, externaliza o excesso de energia acumulada, num processo catártico, desencadeado pela tensão que ronda seu iminente julgamento na corte marcial. Segundo Kent Jones, o pathos da cena estaria numa certa solidão e melancolia que permeia toda a tomada, associada à "lenta construção de uma liberação incontrolável" (Jones, 2009, p. 105). Tal processo se consolidaria no momento em que o corpo tomba exausto num canto do quadro, em meio aos espelhos e às luzes piscando, quase desfalecido, como se já não houvesse mais energia vital alguma a percorrer seus órgãos.

Beugnet (2004) afirma que Bom trabalho insere-se numa tradição dos filmes de Claire Denis serem protagonizados por personagens que perambulam sem rumo ("wanderers"). Em lugar dos migrantes, temos aqui um grupo de homens que recusam sua própria nacionalidade em prol do ingresso na Legião Estrangeira: ou seja, continua aqui toda uma sensação de desenraizamento, de sentir-se passageiro em um território, 
de se estar em permanente flânerie. Acredito que isso talvez justifique o fato da câmera, num primeiro momento, assumir um olhar desatento e flutuante pelos espaços, para logo depois render-se à fluidez hipnótica das formas e movimentos que se replicam incessantes, nos planos-detalhes dos corpos que repetem diversas vezes os mesmos exercícios físicos, até o limite da exaustão. Tal mudança de registro visual aproxima-se muito de uma transição entre comportamentos do olhar, que Bruno (2002) vai identificar na passagem do óptico para o háptico: o primeiro estaria ligado a uma ideia de voyeur, que assiste a tudo distanciadamente, enquanto que o segundo estaria diretamente associado ao voyageur, um olhar que desliza e passeia pelas superfícies que enxerga.

O voyageur estaria associado a uma construção tátil do espaço, que ocorre de forma gradual, à medida que ele é tocado (seja pela ponta dos dedos, ou, metaforicamente, pelo olhar), percorrendo-se a superfície das imagens e suas respectivas texturas vide, por exemplo, a maneira como nos é apresentada a caverna que os personagens exploram em Tio Boonmee que pode recordar suas vidas passadas (2010), de Apichatpong Weerasethakul. Exatamente por situar o espectador numa zona de imersão que, por alguns instantes, pode proporcionar um certo estado de indistinção entre si e o outro, tal condição háptica permitiria um mergulho sensorial nas imagens apresentadas, por exemplo, em Bom trabalho, potencializando o estado de quase hipnose provocado pela repetição das mínimas pulsações da carne roçada pela câmera de Agnes Godard em close ups e inserts quase abstratos.

Para Marks, as imagens hápticas seriam um tipo tão particular de imagem-afecção, de caráter erótico (num sentido batailleano de dissolução das descontinuidades), na medida em que elas constroem um relacionamento intersubjetivo entre a imagem e quem a vê. Ao convocar o espectador a preencher imaginariamente as fendas entreabertas na imagem, agregando memórias sensuais aos vestígios deixados por essa mesma imagem, temos uma operação de desorganização da distância voyeurista entre quem vê 
e o que e visto: "o erotismo aproxima tal distância e entrelaça o observador no que é visto" (Marks, 2000, p. 184). Daí as irrupções violentas (ou a iminência delas) em Desejo e obsessão: trata-se de uma visualidade que nos torna vulnerável ao que vemos, "revertendo a relação de domínio que caracteriza a visualidade óptica" (Marks, 2000, p. 185).

Talvez por esse potencial perigoso de desorganização das estruturas e hierarquias entre espectador e imagem, implícito na visualidade háptica, tais filmes não a utilizem durante a totalidade de suas cenas, mas justamente aproveitem para explorar a tensão entre os dois regimes de visualidade, permitindo irrupções estratégicas e não muito controláveis da hapticidade dentro do plano. Momentos perturbadores, em que os limites podem se confundir, dissolvendo temporariamente fronteiras. Mas, o que acontece quando se retomam tais limites? Estariam eles mais afrouxados junto ao espectador? Quais novos vínculos se criaram, quais se romperam? Que pode um corpo, após transitar desavisadamente (e repetidas vezes) entre esses dois domínios? “No momento em que minha pele e a pele do filme são pressionadas a ponto de encobrir uma à outra, o filme se torna acessível e transparente para mim" (Barker, 2009, p. 29), afirma Jennifer Barker, numa frase que avisa aos que aqui entram já não ser necessário deixar quaisquer esperanças à porta.

Pensemos nos planos-detalhes de Desejo e obsessão, como por exemplo, os do corpo seminu do jovem delinquente que invade a residência de Coré (Beatrice Dalle), instantes antes que seja literalmente devorado por ela. Nesse aparente prelúdio de um ato sexual, temos alguns takes de um abdome coberto de leve e quase invisível penugem (quase ao alcance de nossas mãos), cuja duração se estende pelo tempo que possamos mentalmente acariciá-lo, antes que o ataque faça jorrar uma incalculável quantidade de sangue em cena. Ou ainda os closes do marido durante o incêndio que consome o corpo de Coré, totalmente encoberto pelas chamas que, em primeiríssimo plano, quase nos cegam. 
Podemos também partir da cena em que Shane (Vincent Gallo) e June (Tricia Vessey) fazem sexo, numa sequência de obsessivos planos-detalhes de parte do corpo que sugerem uma iminente repetição da carnificina, criando junto ao espectador um clima de apreensão bastante acentuado pelo instrumental da trilha sonora dos Tindersticks. O que diferencia tais planos do corpo dos que constariam numa decupagem de filme erótico convencional? Fica a impressão que há algo mais ali, seja no sedoso da penugem, no vermelho contagiante do sangue, na intensidade do amarelo da chama, na frieza da pele asséptica que envolve o púbis da jovem esposa enquadrado tão de perto. Talvez o tempo estendido, talvez a forma de enquadrar, tendendo a valorizar uma pulsação interior que rege os movimentos internos de cada plano (e entre dois ou mais planos), de caráter pendular e coreográfico... talvez por isso tudo tais elementos acabem por causar no espectador um outro tipo de sensação, uma certa cumplicidade perturbadora e não expressável facilmente de maneira racional. Aqui, recorro à afirmação de Beugnet: "o efeito das correspondências e do sensual trabalho de câmera, e a efetiva desestabilização das estratégias convencionais de percepção e ponto de vista resultam na construção de uma pregnante atmosfera de ansiedade" (Beugnet, 2004, p. 164).

Estimulados por essa atmosfera, permitimo-nos descolar da porção de realidade concreta há pouco mostrada e nos permitimos aderir a tão intensa sensação, para que ela nos conduza, ainda que estejamos extremamente apreensivos - como na cena de sexo do casal, que por isso mesmo conclui-se numa sonora, enclausurada e violenta masturbação empreendida pelo personagem de Vincent Gallo para dar vazão a toda energia corporal acumulada e em ebulição graças à intensidade com que ele sente aflorar o desejo sexual/canibal e com a qual tenta se debater com todas as suas forças.

Pendular, oscilante, coreograficamente à flor da pele: como o barco que ondula nas sequências iniciais de Bom trabalho, a câmera flutua por entre closes de legionários 
de torso nu e cabeças raspadas (ou seja, pele pura, totalmente à mostra), ao som do trecho da ópera de Britten que se repete em ostinato. A oscilação nas águas nos faz atentar para a presença dessa câmera no ombro, como se respirasse enquanto capta as imagens. E essa oscilação se desdobra nos mínimos movimentos desses homens, cuja individualidade nos é por enquanto negado conhecer, homens que rastejam no chão sob o emaranhado de arame, que percorrem um atrás do outro os obstáculos da corrida, obrigando a câmera a toda hora subir e descer - ou ainda ir e voltar, de um lado pra outro, em pequenas e repetitivas correções de enquadramento, durante uma corrida num pequeno labirinto. Aqui, até as flexões, aos gritos conduzidas, no chão pedregoso e poeirento, ou as silenciosas marchas em fila indiana são dotadas dessa bruta sensualidade, num verdadeiro contraponto ao movimento ondulado (que aos poucos vai se ampliando) dos ombros e quadris (mais femininos que masculinos), que vão e vem, incansáveis, ao som dos hits tocados na discoteca local.

Por fim, resta ao corpo domado, disciplinado de Galoup, a tarefa de armar impecavelmente a cama, antes mesmo de, com a arma em punho, hesitar um disparo, na iminência de investir contra o próprio corpo. Acompanhamos, em silêncio, a arma ser deitada sobre o abdome, e contemplamos a veia que trepida saltitante, ritmada, ao redor do bíceps do soldado. Ritmo que se desdobra na canção de Corona, dançada numa sala de espelhos que duplica esse corpo, enquanto ele convulsiona no chão e rasteja talvez liberto (ou não) da disciplina do exercício repetido, ainda que preso às 128 bpm do compasso 4/4 do Eurodance. Aqui, a sensação de um transbordamento do corpo é bastante presente, e muito disso se deve à proximidade quase asfixiante com que a cena anterior é filmada, ressaltando a pulsação interna do corpo de forma a impregná-la na percepção do espectador - a ponto de continuar ditando a intensidade do trânsito dos afetos durante toda a duração da cena seguinte, filmada num plano de corpo inteiro. 
Essa tensão que se estabelece entre os planos hápticos, e seu transbordamento nas cenas não-hápticas seguintes, é um dos possíveis caminhos para se permitir uma abertura à experiência sensorial dispersiva que acredito caracterizar o cinema do realismo sensório. Trata-se de um cinema que convida a observar, seja de perto (no caso de Denis e Kawase), concentrando-se numa parcela do corpo que transborda o limite do quadro, ou de longe (como as teleobjetivas de Hou Hsiao-Hsien), numa forma de ver pela distância para perceber os diversos espaços-tempos cotidianos de maneira não-hierarquizada, dando ao olhar o livre-arbítrio de sua flutuação dentro do quadro. Em ambos os casos, a observação se faz sempre minuciosa, demorada, como se tais filmes tentassem, assim, capturar a atmosfera que impregna suas imagens.

Talvez a palavra de ordem seja a de demorar o olhar um pouco mais sobre as coisas e os corpos, não como redundante ênfase narrativa, mas com certa curiosidade dispersiva - daí essa minha insistência num olhar flâneur, que não busca organizar o espaço narrativa ou descritivamente, mas deixa-se levar por ele, ao sabor dos afetos, lembrando-nos o tempo todo que nossa mediação com o mundo e com as imagens passa primeiro pelo sentir (o quão demoradamente for necessário) para depois racionalizar. A partir daí, podemos pensar numa outra chave para relacionarmos a inserção entre corpos, espaço-tempo cotidiano e as diversas paisagens que daí possam porventura emergir.

\section{É possível falar de uma escuta háptica?}

E quando o ambiente é como uma floresta, com seus inúmeros sons simultâneos, oriundos de fontes não-visíveis e não imediatamente identificáveis? Como o espectador pode se situar no espaço sonoro, em uma experiência sensorial dispersiva e multifacetada (ampliada por uma visualidade que também opere nesses registros), que muitas vezes opera sob uma quase-equidade de volume nas fontes sonoras, não 
necessariamente lhe indicando de antemão quais as possíveis portas de entrada para se chegar ao cerne da ação?

Resgato aqui, outra proposta deMarks (2000, p. 183): assim como a visão pode ser háptica, também pode ser a escuta (haptichearing). Parte-se aqui do pressuposto que temos a tendência de escutar sons específicos quando ouvimos o som ambiente como um todo indiferenciado. A escuta háptica seria então esse breve momento em que os diversos elementos sonoros se apresentariam como não-diferenciados, antes que escolhamos os sons que mais nos afetam (aqueles que "roçam" de maneira mais presente nossos ouvidos), em torno dos quais será organizada nossa percepção espacial. Afinal, nossa memória afetiva é uma instância fundamental não só para codificarmos o que ouvimos, mas também para dedicarmos mais atenção a uma fonte sonora do que outra, mesmo que ela seja a menos intensa.

Deste modo, a escuta háptica duraria curtos períodos de tempo, até que algum som venha a ocupar o foco de nossa atenção. Como a definição de qual som irá guiar a percepção do espectador se dá de indivíduo para indivíduo, por uma série de fatores (além da memória afetiva, temos a capacidade de funcionamento do aparelho auditivo, e até mesmo as condições de reprodução das frequências sonoras durante a exibição de um filme), podemos pensar esse mecanismo como uma espécie de arejamento/ afrouxamento no processo de produção de sentidos que cada um faz de uma determinada cena, valorizando assim outros conteúdos audiovisuais que não aqueles pré-concebidos como centrais para a narrativa. Deste modo, a hapticidade auditiva pode ser um mecanismo capaz de ampliar a experiência sensorial do espectador, uma espécie de potência centrífuga de reorganização das relações espaciais a partir do som.

Acredito, portanto, que a conjugação entre momentos de escuta háptica somados a intervenções criativas da acusmática são fundamentais para a construção do tom de 
ambiguidade narrativa da vertente cinematográfica aqui discutida, inclusive no que tange a uma re-hierarquização do valor conferido ao vococentrismo/verbocentrismo que Chion (2008) acredita serem tão característicos às narrativas audiovisuais, conferindo mais presença simbólica aos outros elementos sonoros (para além da voz humana e da palavra), e às linhas de fuga que deles derivam. Arriscaria dizer, também, que nesse estado perceptivo extraordinário, a apreensão da multiplicidade de fiapos narrativos simultâneos dentro do quadro fílmico também seria potencializada pela complexidade do desenho sonoro que se faz presente em filmes de realizadores como Gus Van Sant, Apichatpong Weerasethakul, Lucrecia Martel, Hou Hsiao-Hsien e outros comumente mencionados sob a rubrica do cinema de fluxo.

O espaço da floresta é um interessante exemplo de como a escuta háptica pode se manifestar nesse conjunto de narrativas audiovisuais. Retomemos um depoimento dado por Ben Abel, nativo de Bornéu, citado por Benedict Anderson num artigo sobre Mal dos trópicos (Apichatpong Weerasethakul, 2004): "A floresta é o lugar em que você precisa escutar o tempo todo e manter-se o mais quieto possível" (citado por Anderson, 2009, p. 163). É partindo desse princípio, tão caro à locomoção, localização e sobrevivência do homem na mata densa, que Weerasethakul decide preencher sua floresta tropical com dezenas emissões sonoras acusmatizadas sobrepostas - e se suas procedências nos são desconhecidas, e assim muitas vezes se mantém até os planos derradeiros, é aí que elas contribuem para criar a atmosfera fascinante e perturbadora que emana da segunda parte do filme.

O que temos aqui é uma sinfonia noturna de cigarras, grilos, rajadas repentinas de ventos, folhas secas, inúmeros cantos de aves exóticas, vozes humanas espectrais saindo aleatoriamente do rádio-comunicador ligado, coaxar de sapos, pios de corujas ocasionais turbinas de aviões a sobrevoarem a região, e outros ruídos não tão facilmente identificáveis, cujo caráter perturbadoramente hipnótico se faz claro para o 
espectador. Sons não necessariamente oriundos da realidade concreta, inclusive, e que ajudam a criar o clima de insegurança e mistério acerca do que irá suceder. Se o bosque é fundamental dentro da mitologia tailandesa como local onde os espíritos habitam, faz-se necessário criar um ambiente sonoro que traduza tal condição, inclusive com sons que provenham desse mundo espiritual que nos é revelado, aos poucos, até culminar no encontro entre o soldado e o feiticeiro.

Basta nos concentrarmos na exploração de diversos timbres de cantos de cigarras, repetidos em ostinato, marcando o ritmo da floresta como uma espécie de metrônomo orgânico, para percebermos que o grau de fabricação dos ruídos escutados chega ao ponto de tratá-los como se fossem vozes integrantes de uma polifonia minimalista. Uma partitura composta por blocos sonoros (alguns inclusive crescendo e desaparecendo gradual ou repentinamente no decorrer do plano) repetidos em séries rítmicas que, num primeiro momento são quase imperceptíveis ao espectador, que acreditam estar diante de sons ambientes em estado bruto - e essa complexa construção, herdeira de certos expedientes da música concreta e da ambient music (daí os agradecimentos a Brian Eno nos créditos finais) só começa a se evidenciar aos nossos ouvidos depois de estarmos submetidos à sua emissão durante um tempo considerável:

Os ruídos parecem, a princípio, ser naturais, mas são assaltados por sons artificiais, eletrônicos, que num primeiro momento não são audíveis, mas que repetidos várias vezes nos dão o aviso de que algo vai ocorrer, como é o caso dos murmúrios selvagens que afloram por entre a mudez dos personagens que se encontram sozinhos, rodeados de vegetação."

(Barea, 2008, p. 9) 
Às vezes, só percebemos a repetição dos blocos depois de muitos segundos, ainda que ocorram num mesmo plano-sequência, e isso de certa forma se dá exatamente porque esse som, de alguma forma, parece penetrar por nossos poros, por nossa pele, fazendo com que pulsemos (nós e os personagens) de acordo com seu ritmo, adequando nossas taquicardias a um compasso de espera, frente ao iminente confronto dos personagens - e muito do fascínio da floresta vem dessa sensação não racionalizada, inclusive para o feiticeiro, que fecha os olhos para melhor ouvir o zunido metálico que emana irregular, do walkie-talkie do soldado. A própria percepção do tempo vai se alterando a partir disso: apesar da divisão quase simétrica, em termos de duração, entre as duas estórias que compõem o roteiro Mal dos trópicos, a segunda trama nos parece maior, mais densa - e talvez por isso mais intensa e irrecusável.

Aliás, a exploração sonora dos espaços, tanto a partir de pressupostos hápticos quanto de usos acusmáticos, também pode ser observada como elemento essencial no tipo de arejamento dos fiapos narrativos que o cinema de Hou Hsiao-Hsien promove. A adoção de uma distância observacional característica das lentes teleobjetivas, com planos mais abertos e por vezes flutuantes, faz com que, "tal qual uma faculdade hipnótica ou uma força de impregnação", a tela se torne "uma porta entreaberta para o tempo e para o espaço do plano, uma porta cujo batente é uma música, um som, uma voz, aquilo que nos pega pela mão e nos guia ali onde a imagem nos deixa à distância" (Baecque, 2010, p. 34). E, se os estímulos sonoros podem ser essa instância de reelaboração das prioridades perceptivas do espectador diante da multiplicidade de elementos sensoriais existente em cada plano-sequência do cineasta taiuanês, muitas vezes também são eles que nos ajudam a transitar por entre tantos acontecimentos de modo a estabelecer uma possível interpretação dos eventos que acompanhamos.

Um exemplo disso, aplicado ao espaço doméstico, está na complexa mise-en-scène que rege o episódio da afinação do piano em A viagem do balão vermelho (2007). Várias coisas acontecem ao mesmo tempo: além do trabalho ininterrupto do afinador, na sala 
de estar do apartamento da personagem de Juliette Binoche, temos também uma série de atividades domésticas sendo executadas pela babá (na cozinha) e pela criança (sentada à mesa). Sucessivamente, eles vão ganhando ou perdendo força na hierarquia perceptiva que o espectador vai estabelecendo no decorrer da cena, principalmente se optarmos por nos guiar pelo ponto de escuta sugerido pelo cineasta - por sinal, aqui agregado aos ocasionais movimentos panorâmicos da câmera. Vez por outra, esses movimentos nos fazem descolar da observação de um evento para acompanhar outro, mesmo que o estímulo sonoro não seja necessariamente indicador do clímax narrativo daquela atividade. Inclusive, essa transição quase sempre se faz de maneira deslizante, raramente abrupta - a exceção talvez fique por conta do momento em que a porta do apartamento se abre violentamente, revelando a discussão entre a proprietária e seu vizinho.

Todavia, vale lembrar que essa não é, necessariamente, a única possibilidade de se fruir a cena, já que, mesmo seguindo o ponto de escuta original e a capacidade de certos sons deterem nossa atenção num determinado momento, cada espectador pode também, mediante um esforço não muito grande, ignorar uma fonte sonora que comece a irromper com mais nitidez, e continuar a se guiar pela fonte que já lhe despertara interesse anteriormente. Isso é possível graças a uma certa minimização proposital das diferenças de volume e intensidade entre objetos sonoros distintos dispostos em cena. Essa, a meu ver, é a principal diferença desse cinema de fluxo com relação a outras construções do espaço sonoro em narrativas audiovisuais (tanto clássicas como modernas, ou mesmo de outras vertentes contemporâneas) - não que essa aparente equidade entre a importância das fontes sonoras em cena seja uma novidade na história do cinema, mas decerto podemos afirmar que, pela primeira vez, estamos diante de uma vertente na produção audiovisual em que tal procedimento não seja excepcional, mas sim recorrente e fundamental no estabelecimento do contrato espectatorial.

Também observamos tal concepção sonora quando o olhar de Hou Hsiao-Hsien volta-se para a exploração sensorial do espaço urbano. Talvez o exemplo mais visível 
dessa atitude esteja em Café Lumière (2003), que inclusive possui, como principal personagem coadjuvante, o dono de uma livraria que se dedica, nas horas vagas, de microfone e gravador em punho, a captar os diversos sons emitidos pelos trens que cruzam incessantemente a cidade de Tóquio.

Aliás, os trens são elementos intensamente presentes por todo o filme: cruzam nosso caminho com frequência, atravessam todo o quadro, fazem muitas vezes com que aguardemos (nós e a câmera) sua passagem, anunciada com certa antecedência à medida que as frequências sonoras graves que eles produzem, ao movimentar-se, vão gradualmente se impondo no espaço em que se insere o quadro fílmico. Escutálos é também um exercício de espera e paciência, inclusive multifacetado: basta que abram ou fechem alguma porta diante de nós para que se evidencie ou isole um novo ambiente acústico dentro de um mesmo plano de duração alongada, tão característico do estilo visual de Hou Hsiao-Hsien.

Assim como os personagens esperam os trens para se locomoverem de um ponto a outro da megalópole, também os esperamos chegarem e partirem, e junto com eles, o surgimento e/ou dissipação de seus ruídos. Dentro deles, também somos afetados por toda uma gama de sons próprios: desde o barulho do motor ligado, tão presente no interior dos vagões, como também as ocasionais trepidações das composições metálicas sobre os trilhos, em altíssima velocidade, os outros trens que cruzam seu trajeto em todas as direções, as vozes robotizadas que anunciam a próxima estação, os sons de cada parada e o murmúrio das multidões que adentram a cada novo abrir e fechar de portas. Exatamente por serem muito mais presentes que quaisquer diálogos que os personagens possam travar dentro dos vagões em movimento, o espectador é convidado a estruturar sua experiência de escuta a partir desses múltipos ruídos (em sua maioria mecânicos), a perceber a intensa presença dessa natureza inorgânica no espaço urbano contemporâneo, bem como a inserção dos corpos que por ela transitam, sem parar, o dia inteiro. 
Se o filme de Hou Hsiao-Hsien nos propõe um aprendizado sonoro da alteridade a partir da dimensão mecânica do espaço urbano, temos em Nanayo (2008), de Naomi Kawase, um convite à leitura do corpo do outro como única possibilidade efetiva de comunicação, uma vez impossível decifrar o idioma estrangeiro. E essa leitura, operada pela protagonista japonesa em férias na floresta tailandesa, se faz não somente pelo aprendizado de uma comunicação corporal que partilhe gestos em comum, mas também de uma leitura intuitiva das entonações, a cada vez que o outro venha a proferir alguma frase em seu idioma nativo e tão desconhecido para os outros.

O filme inclusive começa numa situação de escuta háptica, recorrente em várias sequências filmadas no espaço urbano de Bangkok, em que a cacofonia de tantas fontes sonoras simultâneas, todas tão inéditas para a protagonista quanto para a maioria dos espectadores que nunca estiveram naquela cidade, traduz um certo estado de confusão e fascínio - já que, mesmo sem saber pra onde será conduzida, a personagem deixase levar pelo fluxo da multidão que transita pela estação. Todavia, basta se impor o espaço da mata tropical, em especial o que circunda essa espécie de habitação ou pousada em que decorre a maioria das sequências filmadas, para que saia de cena essa construção sonora caótica e o ambiente seja tomado pela placidez de pássaros cantando e do vento na copa das árvores (inclusive em planos quase táteis que mostrem o balanço dos galhos enquadrados bem de perto pela câmera).

Não se trata, todavia, de uma floresta densa, como a que vimos em Mal dos trópicos, ou mesmo no filme anterior de Kawase, A floresta dos lamentos (2007). Aliás, a leveza do ambiente também não tem o caráter do torpor levemente hipnótico do bosque de Eternamente sua (2002), também de Weerasethakul. Num filme em que a recusa de trilhas sonoras musicais não-diegéticas acentua o caráter nada solene desse processo informal de elaboração de uma forma de se comunicar com os estrangeiros que dividem a mesma habitação que a protagonista, o desenho sonoro que ambienta a 
trama é pautado por uma rarefação de sons acusmáticos, de modo a traduzir uma sensação de placidez - todavia, há alguns momentos de sobrevalorização estratégica de sons de objetos. Afinal, aprender a ler o gesto do outro é também aprender a ouvir os sons não-verbais que os corpos emitem, bem como as entonações de uma fala cujos vocábulos não se compreendem, mas que através delas transbordam suas intencionalidades. É aprender a sentir os ritmos desses corpos e atentamente conjugá-los, ao sabor da floresta serena.

E, quando finalmente, tanto a personagem, quanto o espectador, esse atento observador dos estímulos sensoriais que sobressaem durante a narrativa fílmica, intuem a certeza de que já sabem "ler" o outro, eis que somos convidados a desfrutar de um ritual, cujo significado pode talvez não nos ser dado totalmente de antemão (apesar de percebermos se tratar do início da vida religiosa do pequeno futuro monge budista), mas cuja irrecusabilidade se faz exatamente pela maneira como a música que se produz nele vai crescendo e ocupando irrecusável toda a banda sonora do filme, em seus minutos finais. O que não se sabe, aprende-se no decorrer da procissão, tal como faz a personagem, ao repetir a coreografia executada pelos braços de outras jovens. E quando essa experiência nos atinge em toda sua plenitude, resta esperar que ela se dissipe, e embarcar em outra experiência de escuta - tal qual o ponto de vista da câmera que se afasta dos personagens, tal qual um convidado silencioso que, dentro de um barco, desce ao sabor da correnteza do rio, enquanto o espaço sonoro volta a ser invadido pelos sons ordinários da natureza que compõem o ambiente acústico daquele (por fim) encantador pedaço de mata tropical.

\section{REFERÊNCIAS}

ANDERSON, Benedict. The strange story of a strange beast: Receptions in Thailand of Apichatpong Weerasethakul's Sud Pralaat. In: QUANDT, James. Apichatpong Weerasethakul. Viena: Synema, 2009. 
BAECQUE, Antoine de. Mister Hou e a experiência do olhar. In: MARQUES, Luisa (Org.). Hou Hsiao-Hsien e o cinema de memórias fragmentadas. Rio de Janeiro: CCBB RJ, 2010.

BALÁZS, Bela. O homem visível. In: XAVIER, Ismail (Org.). A experiência do cinema. Rio de Janeiro: Graal/ Embrafilme, 1983.

BAREA, MIllagros Expósito. El sonido enel cine de Apichatpong Weerasethakul. In: Frame-Revista de Cine de la Biblioteca de la Facultad de Comunicación, Sevilla (Espanha): Universidad de Sevilla, n. 3, 2008. Disponível em: <http://fama2.us.es/fco/frame/new_portal/textos/num3/Elsonidoenelcine.pdf>. Acesso em: 10 e 15 out. 2013.

BARKER, Jennifer. The tactile eye: Touch and the cinematic experience. Berkeley/Los Angeles/London: University of California Press, 2009.

BEUGNET, Martine. Claire Denis. Manchester/New York: Manchester University Press, 2004.

BRUNO, Giuliana. Atlas of Emotion: Journeys in Art, Architecture and Film. New York: Verso, 2002.

. "Motion and emotion: Film and haptic space". In: ECO-Pós, Rio de Janeiro: Eco-UFRJ, v. 13, n. 2, 2010.

CHION, Michel. A audiovisão: Som e imagem no cinema. Lisboa: Texto E Grafia, 2008.

JONES, Kent. Evidencia Física: Escritos selectos sobre cine. Santiago (Chile): Uqbar, 2009.

LUCAS, Gonzalo de. El cine tiembla. In: LÓPEZ, José Manuel (Org.). Naomi Kawase: El cine en el umbral. Madrid: T\&B Editores, 2008.

MARKS, Laura. The Skin of Film. Londres/Durham: Duke University Press, 2000.

MURILLO, Manuel Yanéz. Dialécticas de un cine habitable: La hibridación del documental y la ficción en el cine de Naomi Kawase. In: LÓPEZ, José Manuel (Org.). Naomi Kawase: El cine en el umbral. Madrid: T\&B Editores, 2008.

OLIVEIRA JR, Luiz Carlos. A mise-en-scène no cinema: do clássico ao cinema de fluxo.Campinas: Papirus, 2013. SCHØLLHAMMER, Karl-Erik. Realismo afetivo: evocar realismo além da representação. In: Estudos de literatura brasileira contemporânea, Brasília, UnB, n.39, jan.-jun. 2012.

Recebido em: 20 nov. 2013

Aceito em: 04 jul. 2014

\section{Endereço do autor:}

Erly Vieira jr.<erlyvieirajr@hotmail.com>

PÓSCOM - Universidade Federal do Espírito Santo

Av. Fernando Ferrari, 514 - Goiabeiras

29075-910 Vitória, ES, Brasi 